\title{
LEARNING ORGANIZATION THROUGH INTEGRATING SCIENCE WITH THE WAY OF LIFE TO ENHANCE SCIENTIFIC KNOWLEDGE TRANSFERRING ABILITY OF PRIMARY LEVEL MUSLIM STUDENTS
}

\author{
Hanida Mohming ${ }^{1}$ and Pongsak Pankaew ${ }^{2 *}$ \\ ${ }^{1}$ A Student of Doctor of Education degree, Faculty of Education, Chiangmai University, Thailand \\ E-mail: hada1234@hotmail.com \\ ${ }^{2}$ Advisor, Asst. Prof. Dr., Faculty of Education, Chiangmai University, Thailand \\ E-mail:p.pankaew@hotmail.com
}

${ }^{*}$ Corresponding author

\begin{abstract}
The context of the three southern border provinces of Thailand is a society which is remarkable in religion, language, and culture. The majority people are Muslim. As a result, schooling in these three provinces focuses on religion in parallel with normal education, but without a disciplinary integration. This is not the answer to proper education which requires integration of all aspects to learners' way of life. According to Islamic disciplines, there must be an integration between religious academic and normal education (secular). Muslims must study the Holy Quran and other subjects along with Islamic disciplines.

This research aimed to develop the lesson plan to promote the Muslim students' ability in transferring the scientific knowledge and to study the Muslim students' ability in transferring the knowledge of science. The populations were obtained by purposive sampling of 4-6 grade students $(\mathrm{N}=30)$ enrolling in Science Club in the first semester of academic year 2016. The research instruments were 1) an analysis of the text consistency in the Holy Quran, which is associated with the concepts and scientific principles 2) Integrated science lesson plans to promote the ability in transferring scientific knowledge of Muslim students and 3) the tests in transferring scientific knowledge. The statistics used for analyzing the collected data were mean, standard deviation and percentage.

The research findings were as follow: 1) the results of analyzing text consistency in the Quran that is associated with the concepts and scientific principles. The point corresponding to a unit of 6 learning units 21 lesson plan. 2) The students' ability in transferring scientific knowledge after taught by the integrated science lesson plan was higher than the 75 percent criteria. The average stay at a good level.
\end{abstract}

Keywords: Science Learning, Knowledge Transfer, Muslim way of life, 3 southern border of Thailand

\section{INTRODUCTION}

The context of the three southern border provinces of Thailand is a society which is remarkable in religion, language, and culture. The majority people are Muslim (2010, The National Statistical Office Thailand: 
online). As a result, schooling in these three provinces focuses on religion in parallel with normal education, but without an integration of disciplinary. This is not the answer to proper education which requires integration of all aspects to learners' way of life. According to Islamic disciplines, there must be an integration of religious academic with normal education (Hashim, 1998: p.6). Muslims must study the Holy Quran and other subjects along with Islamic disciplines. Islam encourages human to study, which appears from the text in the first five verse in the Quran which Allah (God) has given. That is human to read because reading is considered as a process of seeking knowledge (Narongraksaket, 2008: p.110). The science that appears in the Quran is in the fields of Astronomy, Geography, Geology, Marine science, Meteorology, Biology and Physics, etc. (Salleh, 2009: pp.9-10). The Quran teaches human being to think and consider things that by searching correct information with the logic of thinking to support or oppose and compare the testaments to assess the arguments for the conclusion of truth. This is consistent with learning science which relies on the rationality in scientific thinking. This shows that the Quran does not contradict with science learning at all. It is also consistent with the principles of learning science, students should be encouraged to question and questioning things around them as well as used to be tools for inquiry. (Phornphisutthimas, 2008: 58).

The relationship is consistent with the culture and society of student, and learning core of science learning at the primary school level. Students should be stimulated to question the things around them, leading to research with the quest to find knowledge. This is one way to learn by using the survey process that leads to questioning and researching to acquire knowledge. This is way of a teaching based on the theory of constructivism that students have to search, explore, examine the various ways for understanding and store information in the brain for the long term memory and could be recalled when in any circumstances. This is the learning cycles of $7 \mathrm{E}$ Model which promotes learning and knowledge transfer. According to the concept of Eisenkraft, there are 7 stages in the model as follows (2003: 57-59): 1) Elicitation Phase, a phase that teachers ask students questions in order to encourage students to present their background knowledge. This will contribute to planning the curriculum appropriately. 2) Engagement Phase, a phase that creates interest and encourages students to doubts. It can be presented or situation to motivate the students to ask questions, determine the issues be investigated to find out. 3) Exploration Phase, a phrase that students conducted a survey to check assumptions, search for, and gather information from various sources. 4) Explanation Phase, a phase that the result data were analyzed, discussed, interpreted and presented in various forms, such as summarizing, making models, drawing tables, graphs, diagrams, and etc. by students 5) Elaboration Phase, a phase that the knowledge happening is associated with prior knowledge that have been studied to explain the situations, events and things more widely. 6) Evaluation Phase is a phase of an assessment in learning. This is to assess students' abilities that will lead to applications in other areas. 7) Extension Phase, is a phase that allows students to apply what they have learned for the benefits in their daily lives, or apply the knowledge gained to create new knowledge. Learning Cycle will give students the knowledge, skills, critical thinking and expand the knowledge gained from one situation to a similar situation for problem solving in everyday life.

Transfer knowledge has provided the means of transferring knowledge which concluded that the transfer of knowledge caused by brain processes, the relationship between the similarity of the things that are abstract or to induce what are the similarities. (Subedi, 2004: pp.591-599; Haskell, 2001: p.26; Kowtrakul, 2010: p.280) This is the capable application of prior knowledge or the form of the existing solutions to other contexts which might be similar or different from the original knowledge, as well as knowledge and skills from one situation to another situation to resolve problems. The students gain knowledge at school and applied to different situations outside the school, and learn what is new from the existing arrangement with a learning experience that is similar to real life that helps students to transfer knowledge. The aims of this learning organization are that the learners can apply the knowledge gained from the class to solve problems in life. Therefore, learning experience in accordance with the actual life in order to link what they have learned in daily life context must be provided by instructors.

\section{EXPERIMENTAL DETAILS}

The populations were obtained by purposive sampling of 4-6 grade Muslim students $(\mathrm{N}=30)$ who enroll in Science Club in the first semester of academic year 2016 at Banyi-ngo school, Narathiwat, Thailand. It is a 42-hour course offered to a student.

The research instruments were 1) an analysis of the consistency of the texts in the Holy Quran, which is associated with the concepts and scientific principles. The analysis of the contents of the Quran by using the interpretation of the contents, and then selecting specific related issues in compliance with the 8 strands of a primary school level (grades 4-6) within its Science Department, as the basic education core curriculum B.E. 2551 (2008). The Thai translation of the Holy Quran, translated by Arab Alumni Association in Thailand. (1999) and published by King Fahd Complex for Printing the Holy Quran. 2) Lesson plans which integrated 
science to promote the ability to transfer scientific knowledge of Muslim students and 3) the ability to transfer scientific knowledge test with two types of multiple-choice and essay.

The statistics used for analyzing the collected data were mean, standard deviation and percentage.

\section{RESULTS}

\subsection{The Results of the Development of Learning Organization Through Integrating Science with the Way of Life to Enhance Scientific Knowledge Transferring Ability of Primary Level Muslim Students}

The content is consistent with the Quran, in relation to the study of scientific concepts and principles. The contents from the Quran, combined with scientific concepts and principles consists of 237 verses, which can be classified into 6 learning units and 21 lesson plans with the 5 strands are as shown in Fig. 1.

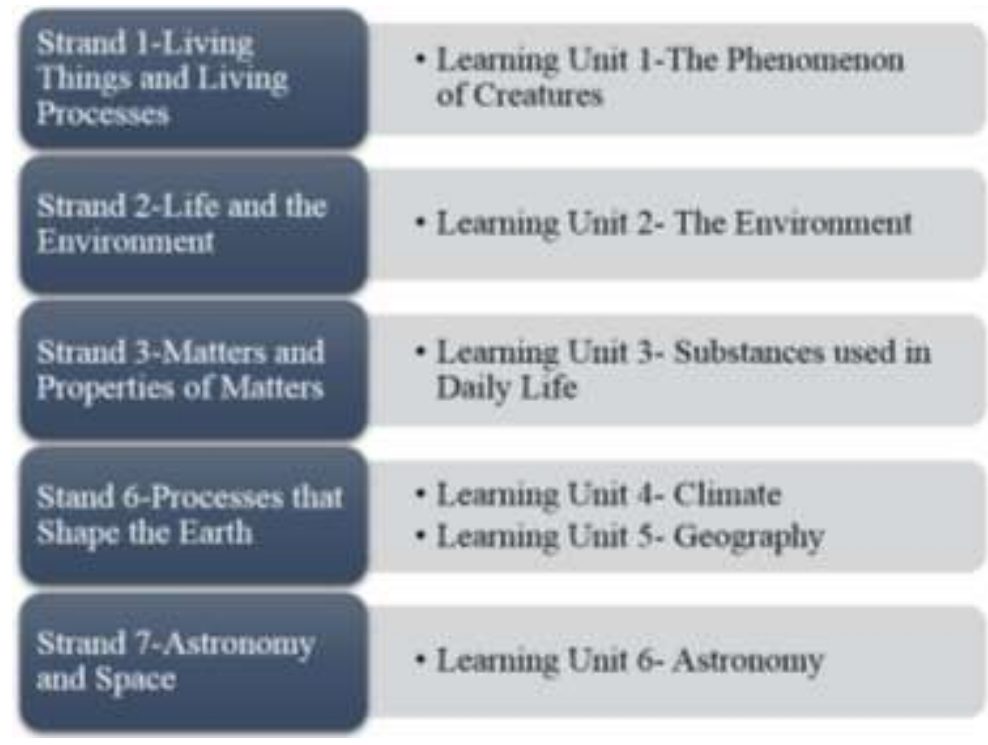

Fig. 1. Classified into 6 learning units with the 5 strands within its Science Department, as the basic education core curriculum B.E. 2551 (2008).

The researcher presented the findings concluded from student observations and interviews using the following:

Learning unit 1- The Phenomenon of Creatures. The researcher found the students could apply the knowledge from lessons to real-life situations in everyday with immerse understanding. Students used the knowledge that they had gained from the school to expand further application, such as giving family advice. For examples, give advice to mothers on how to feed their children with breast milk instead of using milk powder. Moreover, give advice on food preparation in order to prevent parasitic diseases and how to thoroughly rinse vegetables. These are examples of practical methods which correspond to the principles of a religious Muslim family and their way of life for the students and their families.

Learning unit 2- The Environment. This is a Science integrated learning organization about the environment and the conservation of water resources which is consistent with Islamic principles. The researcher found that students applied the knowledge from lessons to everyday real-life situations regarding the Ablution, such as the understanding of the correct amount of water needed for each prayer. From this, the students became aware more of the value of water and how to use water more wisely. Students did this by observing the prayer during the Dhuhr period (the prayer after midday), and at the Asr period (afternoon prayer) at the school's prayer building, where the students economically did an Ablution together with their friends and were able to inform one another on the importance of saving water. After the prayer, the remaining water from the Ablution was used for watering the lemon trees and vegetables in the herb garden which is located on the school grounds.

Learning unit 3- Substances used in Daily Life. This is a Science integrated learning organization of the Muslim way of life that is associated with the substances used in daily life. From interviewing the students and those who are involved with the school, the researcher found that some students lacked knowledge and awareness when purchasing and consuming food that is hygienic and suitable for the religion. Students were 
careless and did not place importance on product labels on the back of their snack packets, and because of this, they did not know what bacon is and what bacon is made from. Can Muslims eat it or not? What is Halal? Is it important to Muslims? The students were only amused with the advertisements of the products and their colorful packaging. Some of them only knew that Muslims cannot consume food that is mixed with pork, but did not know what Halal is. The researcher also found that after students learnt integrated Science regarding lifestyle, the students became more aware when purchasing snacks, by observing the product labels for ingredients and important components of the production process. Furthermore, cooperative officers within the school also used this information to consider when purchasing items that will be sold to students, so that these items will be safe from prohibition.

Learning unit 4- Climate and Learning unit 5- Geography. These units involve learning about agricultural way of life. The researcher found that students applied scientific knowledge towards crop cultivation. Students applied this to plant breading, especially for rubber saplings, solid improvement and the fertilization of minerals by using handmade bio-liquid fertilizers. In addition, students could also take their agricultural products and sell them in order to generate income for themselves and their families. This is consistent with the school philosophy which is in accordance with the sufficiency economy philosophy, as there are herb and home-grown vegetable gardens and plots for students to plant.

Learning unit 6- Astronomy. This unit involves learning about the Muslim way of life in regards to prayer and fasting, which are important for all Muslims. Unit 6 Astronomy is related with fasting. Students can explain the occurrences of the moonrise and moonset by applying the knowledge towards their way of life in the subject of fasting, which is observed by using the Hilal (crescent). The waxing moon is $0-2$ day. If you see the crescent on the $29^{\text {th }}$ of the last month, the next day will be counted as the $1^{\text {st }}$ of new month, according to the Islamic calendar. Students can observe the direction of Qibla by using the shadows for prayer.

\subsection{The Results of the Study and the Ability to Enhance Scientific Knowledge}

Table 1. Means, Standard Deviations, and Percentage of the Evaluation Scores of the Students' Abilities to Enhance Scientific Knowledge ( $N=30)$

\begin{tabular}{|l|c|c|c|c|c|}
\hline \multicolumn{1}{|c|}{ Learning Unit } & $\begin{array}{c}\text { Full } \\
\text { Score }\end{array}$ & $\mu$ & $\sigma$ & Percentage & Interpretation \\
\hline $\begin{array}{l}\text { Unit 1- The Phenomenon of } \\
\text { Creatures }\end{array}$ & 50 & 37.93 & 3.05 & 75.86 & Very good \\
Unit 2- The Environment & 40 & 34.76 & 3.67 & 86.90 & Excellent \\
Unit 3- Daily Life Substances & 30 & 22.46 & 1.47 & 74.86 & Very good \\
Unit 4- Climate & 30 & 23.20 & 1.66 & 77.33 & Very good \\
Unit 5- Geography & 30 & 22.30 & 1.60 & 74.33 & good \\
\hline Unit 6- Astronomy & 30 & 24.86 & 2.22 & 82.86 & Excellent \\
\hline \multicolumn{1}{|c|}{ Average } & & $\mathbf{2 7 . 5 8}$ & $\mathbf{2 . 2 7}$ & $\mathbf{7 8 . 6 9}$ & Very good \\
\hline
\end{tabular}

Table 1 shows that the students' abilities to transfer scientific knowledge at an average reaching the 'very good level' of $78.69 \%$. The learning unit for which the students show the highest average score and means are the learning unit on "The Environment" (86.90 percent of maximum score). The next high scores and means recorded by the students are in the learning unit of "Astronomy," "Climate," "The Phenomenon of Creatures," "Daily Life Substances," and "Geography." respectively.

Table 2. Average Score and Standard Deviation of the abilities to transfer scientific knowledge Scores of Students after taught by the integrated science lesson plan $(\mathrm{N}=30)$

\begin{tabular}{|c|c|c|c|c|c|}
\hline Test & Full Score & $\mu$ & $\sigma$ & Percentage & Interpretation \\
\hline Post test & 100 & 79.20 & 5.04 & 79.20 & good level \\
\hline
\end{tabular}

Table 2 shows that the students' abilities to transfer scientific knowledge at an average reaching the 'good level' of 79.20 percent, compared to the defined criteria of 75 percent.

\section{DISCUSSION}

4.1 The researcher organized learning activities that integrate science with the Muslim way of life by using the content and sequence. The situation has been defined as the context related to students in order to help stimulate interest and self-study for problem-solving in accordance with assumptions of the Transfer of 
Learning Theory, if the transfer of knowledge is dependent on the social environment and interacting together with the inside and outside of a person, which is a situation that occurs in societies that affect learning (Haskell, 2001: p.84). Knowledge transfer will occur from a belief in the similarity of the situation or work, understanding of the concepts and principles. Further application by using prior knowledge towards problem-solving or knowledge of the application in a new context. Therefore, management of the learning experience with consideration of such factors that are similar to what is found in everyday life. It can help students to apply the knowledge and skills obtained from the school towards a new situation and solve problems that occur outside of the school. The students exchanged and received information from the researcher regularly. This corresponded with the Constructivism Theory that is important for knowledge, creation, understanding and experience. The interpretation of knowledge depends on the perception and experiences of their interests, because occurred knowledge would be used to discuss issues that affect with relative consistency of other contexts that are similar. Grade 4 students shared their knowledge and exchanged their learning experiences with students in grades 5 and 6 , because all students have religious experiences from their Islamic school on Saturday and Sunday, which is known as "Tadika". Here, each student gained knowledge about the religion in different classes ranging from beginner, intermediate to advance levels. This affected students when sharing knowledge among each other. At the same time, the researcher also took into consideration the experience and basic background knowledge regarding the religion. Especially, the study of verses in various chapters in the Holy Quran which the students have not learned, because the classes are divided by religion and abilities, but not by students age. Therefore, many grade 4 students study religion at the intermediate and advance levels. On the other hand, there are grade 6 students whom are still studying the religion at the beginner and intermediate levels that is based on the concept of Eisenkraft (2003: p.57) which offers teaching in the learning cycle of 7E. The Elicitation Phase Stage is the step that teachers will ask questions to encourage students to show their prior knowledge. That will lead to appropriate planning and management.

Learning unit 1- The Phenomenon of Creatures. In this unit, the students will learn about local plants, growth of crops, agriculture, conserving rice genes and the utilization of plants to create artificial home appliances or use them to make local foods and snacks. In addition, students will also learn to see the value of life and live consciously with faith, gratitude and the remembrance of Allah; human birth from the scientific concepts and principles, in which learning activities also focus on ethics. Ethics, which is the primary religious practice in order to promote its features that could occur in students. The researcher found that students could apply their knowledge from lessons to everyday real-life situations, by understanding how to use knowledge gained from school and expand to further educate their families. Due to the fact that students have a good understanding of the scientific principles in accordance with the levels and types of transfer of knowledge in level 3 "Context Transfer" of Haskell (2001: p.31), which is the transfer of knowledge of the application of the knowledge from the prior knowledge to a new situation that has slight differences. However, the transfers of knowledge in level 4 "Near Transfer" is the transfer of knowledge of prior knowledge to a new situation that is very similar.

Learning unit 2- The Environment. This is a Science integrated management about the environment and the conservation of water resources, which is consistent with Islamic principles. Islamic people dislike extravagant use of resources and do not allow humans to benefit from the environment alone, but also to have faith, especially to conserve water for the use in the ablution, which is one of many practices in the Islamic religion. All Muslims must understand and give great importance to this. As occurred in the research of Valentina et al. (2016: pp.209-216) which proposed to study analyses the green verse in order to highlight the ecological caliber of the Holy Quran, their findings showed that The Holy Quran mentions that there is a close relationship between the behavior of people and the state of the environment. The attitude of Islam towards the environment and natural resources is a constructive one, based on protection, dismissing abuse and destruction. The researcher observed that students could transfer their knowledge from lessons to everyday real-life situations, regarding to ablution, by understanding about the suitable amount of water needed for each ablution. Students became more aware of the value and use water. They were able to expand the knowledge gained from school to further educate their families, because they have a better understanding of the scientific principles due to their observation of the prayer during the Dhuhr and at the Asr period at the school's prayer building. Here, students had taken part in the ablution bath with friends and were able to inform other on how to conserve water. Moreover, students can relate the knowledge that have learned from the religious school, a mosque in the village, to answer questions from the researcher, which were about the wise use of water and water conservation. So, the variety of management of the learning experiences with the social context of the students in relation to the original lesson and a new lesson in parallel, enabled students to reflect on their thoughts that led to knowledge transferring, which is consistent with Perkins and Salomon (1988: p.26), who proposed a learning management strategy to transfer the knowledge by using Parallel Problem-Solving. It is a new means that has a similar structure, but different 
content in order for students to evaluate and apply the knowledge to solve problems in a new situation that is similar and different.

Learning unit 3- Substances used in Daily Life. This is a Science integrated management on the Muslim way of life, which is associated with the use of substances. Students have learned about consumption of halal food that requires knowledge about chemical and synthetic substances, critical thinking skills, the reading of labels on packaging to avoid from being prohibited, analyzing components of packaging, deciding whether to buy the products, and the disadvantages of drugs and alcohol, which is prohibited by the scientific principle of Islam. Muslim must not consume drugs and alcohol, as these substances make people unconscious. This is considered to be sinful. The researcher found that after students had studied about integrated science and lifestyle, they were more aware of the disadvantages of drugs and the decision to buy other snacks by reading labels or packaging for the ingredients and the components of production. In addition, the relevant cooperative officers of school also used this information to buy items that would be more suitable to sell to students in order to keep them safe from prohibition. It can be seen that substances are directly related to daily life. Therefore, informing students about substances is vital for making Muslim students understand. In particular, Muslim teachers should manage the learning of science with the scientific concepts and principles, which correspond to the Muslim way of life, so that students can relate the scientific knowledge from the classroom and apply it to their own lives. According to the research of Mansour (2011: pp.281-390) which proposes learning organization of Science which must be standard, and stimulates learners in asking facts of nature. Multicultural science must be considered by providing learning contexts which are related to learners' cultures and societies.

Learning unit 4- Climate and Learning unit 5- Geography. This unit is about how to use the knowledge of agriculture to understand thunder storms. The storms destroyed homes and agricultural produces (due to the occurrences of hail). The observation of land and sea breeze in maritime fishing, plant cultivation, and soil improvement of fertile soil through the use of minerals is one of many factors that make plants grow better. Lack of fertilizer and mineral in soil will result in incomplete plant growth. Furthermore, the school has operated by mounting guidelines based on the sufficiency economy philosophy. There are herb and home-grown vegetable gardens and plots for students to plant. Students can improve soil to be fertile by using biological fertilizers. In addition, students can also take agricultural products to sell and earn money for themselves and their families. To learn by using practical instrument, make students understand the meaning of the information, along with the relationship of information, gather the original and new information and link them to the new knowledge and transfer them, as Haskell (2001: p.29) said, the level of knowledge transfer depends on the similarity of the old situation to the new situation. It is level 2 "Application Transfer" which is the transfer that is applied to the knowledge from the original situation to the new situation that is very similar.

Learning unit 6- Astronomy. This is the study about the Muslim way of life in regard to prayer and fasting, which are important factors for all Muslims. Students can apply their knowledge of scientific matter and direction through the observation of shadows in order to find the Qibla (the direction of the Kaaba shrine in Mecca toward which all Muslims turn in ritual prayer). This includes the observation of the phenomenon that is the moonrise and moonset, which is used to define the starting date of the Ramadan Month by using the shapes that appear in the moon. The researcher continued to collect data and information during semester 1 of 2016, which ranges from May to September. Early June of this year was the month of Ramadan for all Muslims around the world, so this unit is linked with fasting and is the most closely related unit for the students according to the concept of Haskell (2001: p.32) which discussed the level of knowledge transfer for the level of "Context Transfer". This means that the transfer of knowledge generated by the application of the original knowledge to a new situation, a situation that is slightly different, because most Muslim students have practiced fasting since they were 10 to 12 years old or since they were in Grades $4-6$. This corresponds to Perkins and Salomon (1988: p.22-32) who proposed a strategy, that comprised of 2 methods, for the transferring of knowledge. 1) Hugging is a situation that is created for students in order to have the opportunity to use their knowledge as much as they can. Students will be enthusiastic to practice and apply their knowledge. 2) Bridging is a way in which students can apply knowledge and concepts to different situations. The researcher used the 'Generalizing Concept' method where students can use the scientific concepts and their moonrise and moonset experiences to apply in different situations, by doing an assignment about the observation of the moon crescent. By studying about the given situation, students can transfer the scientific knowledge toward the Muslim way of life. It was found that the students can observe the phenomenon of the moonrise and moonset, understand the concept of the moon shapes used to define the starting date of the Ramadan month, which is consistent the specific knowledge transferring that is knowledge based from Haskell (2001: p.30) which indicated that a transfer of knowledge from the "Content to Skill Transfer" will occur during practice. From the above information, the observation of the moon each 
night and the counting of the next day as the $1^{\text {st }}$ day of the new month helps to establish the starting date of the month of Ramadan.

4.2 Students gained the abilities to transfer scientific knowledge at an average reaching the "good level" of $79.20 \%$, compared to the defined criteria of $75 \%$, as the researcher based learning experiences on the relationship between knowledge of the world and religious knowledge, by interacting Science with the Muslim way of life, which integrates content and skills as a single subject, creates a context of Science learning that is consistent with the religious principles. Thus, the students explicitly understood the content and the meaning. Students understood the concepts, basic principles and the scientific procedures by doing it themselves, which helps students get hands-on experience and gain knowledge to use it in everyday reallife situations, because a Muslim's way of life uses the scientific knowledge in their religious ceremonies. Moreover, the researcher has set an example of the learning of something new from a similar situation to expand knowledge and ideas by learning from a new situation that is similar to the original situation through the use of tasks and activities, then the discussion and analysis of the relationship between the Muslim way of life and the present work that students have chosen to use in order to represent their work by themselves. This is an example of the "Parallel Problem-Solving" worksheet form by presenting a new situation that is similar, but the content is different, so that students can evaluate and apply the knowledge to solve problems in a new situation that is similar in conflict, which is in accordance with Haskell (2001: p.26) who stated that knowledge transferring occurs from the brain process in which it sees the relationship between the similarities of things that are abstract or inductive to similar things, which is the ability to apply knowledge or the format of the problem-solving process in other circumstances that are similar or different. The students gain knowledge at school and applied to different situations outside the school, and learn what is new from the existing arrangement with a learning experience that is similar to real life that helps students to transfer knowledge. As occurred in the research of Gilbert, Bulte and Pilot (2011), of learning science based on the context of promoting concepts and knowledge transfer, and transferring knowledge using the mind map, it was found that the mind mapping helps students to understand the context more deeply the laboratory and tasks solutions.

The researcher has used "Metacognitive Reflection" in order to prepare and support students by planning and checking their ideas to enhance their knowledge and understanding of learning from a situation or a problem-solving task, which includes learning about further situations. In this step, the researcher evaluated the results from activity and group worksheets, the answering of questions to verify understanding, summarizing the knowledge learnt, the scientific concepts and principles that were learned and were recorded into each students' notebooks to check for their individual understanding.

\section{CONCLUSIONS}

In summary, the concepts of knowledge transfer are from the belief that resembles of situations, tasks, and concepts of prior knowledge leading to problem solving and application to new contexts. Therefore, the learning organization for students to apply knowledges, skills and experiences should be gained from schools and transferred to new situations and problem solving outside schools. Management in learning science links between scientific knowledge that is universal with the life of Muslim students in the three southern border provinces, Teachers must consider the integration by selecting and arranging the contents in the learning experience and creating a context of learning science related to daily life of students. Learning strategies in transferring knowledge is students' ability to link their knowledge in science concepts, scientific principles, and scientific process skills learnt from schools to way of life. A knowledge transfer has been appropriately occurred in students, they could finally apply the knowledge to daily Muslim way of life.

\section{ACKNOWLEDGEMENT}

This research was financially supported by the National Research Council of Thailand.

\section{REFERENCE LIST}

Arab Alumni Association in Thailand. (1999). Translation of the meaning of the Holy Quran in Thai. Bangkok: King Fahd Complex for Printing the Holy Quran.

Eisenkraft, A. (2003). Expanding the 5E Model: A Proposed 7E Model Emphasizes Transfer of Learning and the Importance of Eliciting Prior Understanding. The Science Teacher, 70(6): 56-59.

Gilbert K. John, Bulte, M.W. Astrid \& Pilot, Albert. (2011). Concept Development and Transfer in Context- 
Based Science Education. International Journal of Science Education, 33(6): 817-837.

Hashim, R. (1998). Islamization of the Curriculum. [Online] available http://www.iiitbd.org/rosnani hashim/Islamization.pdf. (2012, May20)

Haskell, R.E. (2001). Transfer of Learning: Cognition, Instruction and Reasoning. San Diego: Academic Press.

Kowtrakul, S. (2010). Education of Psychology. Bangkok: Chaulalongkorn University Printing House.

Mansour, N. (2011). Science Teachers' Views of Science and Religion vs. The Islamic Perspective: Conflicting or Compatible?. DOI 10.1002/sce.20418. [Online] available http://www.wileyonlinelibrary.com (2012, June11)

Ministry of Education. (2008). The Basic Education Curriculum B.E.2008 (A.D.2008). Bankok: Thailand. Agricultural Cooperative Association of Thailand.

Narongraksaket, I. (2008). Philosophy of Islamic Education. College of Islamic Studies. Prince of Songkla University. Pattani: Hadyai Graphics Printing House. (in Thai)

National Statistical Office Thailand. (2013). The Population and Housing Census. [Online] available http://www.nso.go.th (2013, January 30)

Perkins, D. N., \& Salomon, G. (1988). Teaching for Transfer. [Online] available http://www.ascd.org/ASCD/pdf/journals/ed_lead/el_198809_perkins.pdf. (2013, July 22)

Phornphisutthimas, S. (2013). Learning Management of Science in 21st Century. Journal of Research Unit on Science, Technology and Environment for Learning 4(1): 55-63.

Salleh, M. J. (2009). Integrated Islamic Education: Need for Thematic Approaches. 14 Nov 2009, Singapore Islamic Education System- SIES Seminar, Wisma MUIS, Singapore. [Online] available http://www.iium.edu.my.html. (2012, May 20)

Subedi, B.S. (2004). Emerging trends of research on transfer of learning. International Education Journal, 5(4): 591-599.

Valentina, M.M et al. (2016). A Qualitative Exploration of The Holy Quran's Environmental Teachings. International E-Journal of Advances in Education. 5(2): 209-216. 